\title{
Fragmentation of Phosphopeptides by Atmospheric Pressure MALDI and ESI/Ion Trap Mass Spectrometry
}

\author{
Susanne C. Moyer \\ Department of Chemistry, Johns Hopkins University, Baltimore, Maryland, USA
}

\begin{abstract}
Robert J. Cotter
Department of Pharmacology and Molecular Sciences, Johns Hopkins University School of Medicine, Baltimore, Maryland, USA
\end{abstract}

\author{
Amina S. Woods \\ Chemistry and Drug Metabolism, Intramural Research Program, National Institute on Drug Abuse, National \\ Institutes of Health, Baltimore, Maryland, USA
}

\begin{abstract}
An investigation of phosphate loss from phosphopeptide ions was conducted, using both atmospheric pressure matrix-assisted laser desorption/ionization (AP MALDI) and electrospray ionization (ESI) coupled to an ion trap mass spectrometer (ITMS). These experiments were carried out on a number of phosphorylated peptides in order to investigate gas phase dephosphorylation patterns associated with phosphoserine, phosphothreonine, and phosphotyrosine residues. In particular, we explored the fragmentation patterns of phosphotyrosine containing peptides, which experience a loss of $98 \mathrm{Da}$ under collision induced dissociation (CID) conditions in the ITMS. The loss of $98 \mathrm{Da}$ is unexpected for phosphotyrosine, given the structure of its side chain. The fragmentation of phosphoserine and phosphothreonine containing peptides was also investigated. While phosphoserine and phosphothreonine residues undergo a loss of $98 \mathrm{Da}$ under CID conditions regardless of peptide amino acid composition, phosphate loss from phosphotyrosine residues seems to be dependent on the presence of arginine or lysine residues in the peptide sequence. (J Am Soc Mass Spectrom 2002, 13, 274-283) (C) 2002 American Society for Mass Spectrometry
\end{abstract}

A $\mathrm{n}$ atmospheric pressure matrix assisted laser desorption/ionization (AP MALDI) source [1] was coupled to an ion trap mass spectrometer (ITMS) [2-5]. AP MALDI offers the advantages typically associated with a MALDI source such as minimum sample cleanup, ease of sample preparation, multiple analyses from a single spot, as well as simplified spectra for complex mixtures, that are easily interpreted. At the same time, AP MALDI does not require a vacuum region and is easily interchangeable with other atmospheric pressure sources, such as electrospray ionization (ESI). Coupling the AP-MALDI source with an ion trap mass analyzer combines the benefits of MALDI sample preparation and simplicity of spectral analysis resulting from the production of predominantly singly charged ions, with the $\mathrm{MS}^{\mathrm{n}}$ capabilities of the quadrupole ion trap mass spectrometer [2,3]. This configuration has proven to be useful in obtaining

Published online January 22, 2002

Address reprint requests to Dr. A. S. Woods, Chemistry and Drug Metabolism, Intramural Research Program, NIDA, National Institutes of Health, 5500 Nathan Shock Drive, Baltimore, MD 21224. E-mail: awoods@intra.nida.nih.gov structural information for peptides and protein digests $[2,3,6,7]$ as well as for the identification and characterization of posttranslational modifications [7].

Phosphorylation is one of the most common and physiologically important posttranslational modifications in proteins and peptides. Phosphorylation plays a crucial role in a number of biochemical interactions that control the steps necessary for the smooth operation of a normal cell. However, because phosphorylation is an energy consuming process and cells are the most efficient energy consumer in the biological and mechanical world, only a low number of copies ( $20 \%$ on average) of a possible consensus site are usually phosphorylated. To complicate matters, the addition of a negatively charged group to a serine, threonine, or tyrosine residue, which is often surrounded by negatively charged residues such as Asp or Glu (casein kinase consensus sites), often results in suppression of the ion signal in the mass spectra of such peptides.

The ubiquitous nature of phosphorylation in biological systems has necessitated the development of methods for the identification and characterization of phosphorylation sites. The introduction of ESI and MALDI 
Table 1. Summary of AP MALDI MS/MS data from singly charged ions

\begin{tabular}{|c|c|c|c|c|}
\hline Peptide & $2^{\circ}$ Structure & $\begin{array}{l}\text { Charge } \\
\text { state }\end{array}$ & $\begin{array}{l}\text { CID backbone } \\
\text { fragmentation }\end{array}$ & $\begin{array}{c}\text { Precursor ion } \\
\text { phosphate } \\
\text { loss }\end{array}$ \\
\hline \multirow[t]{2}{*}{ Ac-RRLIEDAE(pY)AARG-amide } & & +1 & $b$ and $y$ & $\Delta 98$ \\
\hline & Denatured & +1 & b, y and internal & $\Delta 98$ \\
\hline \multirow[t]{2}{*}{ AAAAADAA(pY)AAAA } & & +1 & $\mathrm{~b}$ and $\mathrm{y}$ & no loss \\
\hline & Denatured & +1 & b, y and internal & no loss \\
\hline \multirow[t]{2}{*}{ RRLIEAAE(pY)AARG } & & +1 & $\mathrm{~b}$ and $\mathrm{y}$ & $\Delta 98$ \\
\hline & Denatured & +1 & $\begin{array}{l}\Delta 98: \mathrm{y}_{9}, \mathrm{y}_{11} \\
\mathrm{a}, \mathrm{b}, \mathrm{y} \text { and internal }\end{array}$ & $\Delta 98$ \\
\hline \multirow[t]{2}{*}{ KKLIEAAE(pY)AAKG } & & +1 & $\begin{array}{l}\mathrm{b}, \mathrm{y} \text { and internal } \\
\Delta 98: \mathrm{b}_{9}-\mathrm{b}_{12}, \mathrm{y}_{11}, \\
\mathrm{y}_{12} \text { and } \\
\text { KKLIEAAE(pY)A }\end{array}$ & $\Delta 98$ \\
\hline & Denatured & +1 & $\begin{array}{l}\mathrm{b} \text { and } \mathrm{y} \\
\Delta 98: \mathrm{b}_{7}-\mathrm{b}_{12} \text { and } \mathrm{y}_{9}\end{array}$ & $\Delta 98$ \\
\hline \multirow[t]{2}{*}{ AALIEDAE (pY)AAAG } & & +1 & $a$ and $b$ & no loss \\
\hline & Denatured & +1 & $\mathrm{~b}$ & no loss \\
\hline RRLIEDNEYTARG & & +1 & $\mathrm{~b}$ and $\mathrm{y}$ & $\mathrm{N} / \mathrm{A}$ \\
\hline DRV(pY)IHPF & & +1 & $a, b, y$ and internal & $\Delta 80, \Delta 98$ \\
\hline DRVYIHPF & & +1 & $a, b, y$ and internal & $\mathrm{N} / \mathrm{A}$ \\
\hline N(pY)ISKGSTFL & & +1 & b, y and internal & $\Delta 98$ \\
\hline SVL(pY)TAVQPNE & & +1 & b and internal & no loss \\
\hline RRREEE(pT)EEEAA & & +1 & $\begin{array}{l}\mathrm{b} \text { and } \mathrm{y} \\
\Delta 80: \mathrm{b}_{8}, \mathrm{~b}_{9} \\
\Delta 98: \mathrm{b}_{7}, \mathrm{~b}_{8}, \mathrm{y}_{11}\end{array}$ & $\Delta 98$ \\
\hline RRREEE(pS)EEEAA & & +1 & $\begin{array}{l}\mathrm{b}, \mathrm{y}_{11} \\
\Delta 80: \mathrm{b}_{7}-\mathrm{b}_{9}\end{array}$ & $\Delta 98$ \\
\hline RRREEETEEE & & +1 & b, y and internal & $\mathrm{N} / \mathrm{A}$ \\
\hline RRA(pS)PVA & & +1 & $\begin{array}{l}\mathrm{b} \text { and } \mathrm{y} \\
\Delta 98: \mathrm{y}_{6}\end{array}$ & $\Delta 98$ \\
\hline KRP(pS)QRHGSKY & & +1 & $\begin{array}{l}\mathrm{b}, \mathrm{y} \text { and internal } \\
\Delta 98: \mathrm{b}_{9}, \mathrm{y}_{8} \text { and } \mathrm{y}_{9}\end{array}$ & $\Delta 80, \Delta 98$ \\
\hline $\mathbf{K R}(\mathrm{p} T) \mid \mathbf{R} \mathbf{R}$ & & +1 & $\mathrm{~b}$ & $\Delta 98$ \\
\hline
\end{tabular}

techniques during the past decade, as well as the incredible speed with which sensitive and accurate techniques have been developed for the analysis of trace amounts of biological materials, has made mass spectrometry the method of choice for the analysis of biological molecules. Several groups have investigated various approaches to effectively determining phosphorylation [9-21]. Annan and Carr studied phosphopeptides by postsource decay (PSD) time-of-flight (TOF) mass spectrometry and found that phosphoserine and phosphothreonine containing peptides had abundant $\left[\mathrm{MH}-\mathrm{H}_{3} \mathrm{PO}_{4}\right]^{+}$ions and weaker $[\mathrm{MH}-$ $\left.\mathrm{HPO}_{3}\right]^{+}$ions. Conversely, their PSD data for phosphotyrosine containing peptides had predominantly [MH $\left.-\mathrm{HPO}_{3}\right]^{+}$ions and rarely revealed $\left[\mathrm{MH}-\mathrm{H}_{3} \mathrm{PO}_{4}\right]^{+}$ ions [9]. Qin and Chait reported that MALDI/ITMS CID of phosphorylated peptides containing either a phosphoserine, phosphothreonine, or phosphotyrosine residue resulted in a loss of $98 \mathrm{Da}$, corresponding to either a loss of $\mathrm{H}_{3} \mathrm{PO}_{4}$ or $\mathrm{HPO}_{3}+\mathrm{H}_{2} \mathrm{O}$ [11].

Although many investigators have utilized MS for the study of phosphorylation sites, gas phase fragmentation pathways for phosphate loss from peptides and proteins have yet to be elucidated. Several groups have investigated the gas phase dephosphorylation patterns of phosphorylated peptides and proteins [8-21]. DeGnore and Qin [12] studied phosphopeptides by ESI/ ITMS. They reported that the loss of phosphate group is charge state dependent and that loss of phosphate from phosphoserine and phosphothreonine occurs via $\beta$-elimination. Additionally, their data indicated that loss of $98 \mathrm{Da}$ from a phosphotyrosine residue was the result of a two-step process involving the loss of $\mathrm{HPO}_{3}$ followed by the loss of $\mathrm{H}_{2} \mathrm{O}$. O'Hair and coworkers have investigated gas phase fragmentation reactions involving phosphate loss from phosphoserine residues using both ESI/ITMS and computational methods [8]. In contrast with the results of DeGnore and Qin, they concluded that loss of the phosphate moiety occurs via a cis-1,2-elimination and not by a $\beta$-elimination. Lehmann and coworkers utilized ESI/QqQ MS in the study of phosphopeptides and phosphopeptide analogues [14]. They described a six-centered transition state in the mechanism of $\mathrm{H}_{3} \mathrm{PO}_{4}$ loss from phosphoserine, phosphothreonine, and phosphohomoserine containing peptides. Recently, Metzger and Hoffman [16] proposed two mechanisms for the loss of $\mathrm{H}_{3} \mathrm{PO}_{4}$ from phosphotyrosine containing peptides utilizing MALDI PSD. The 

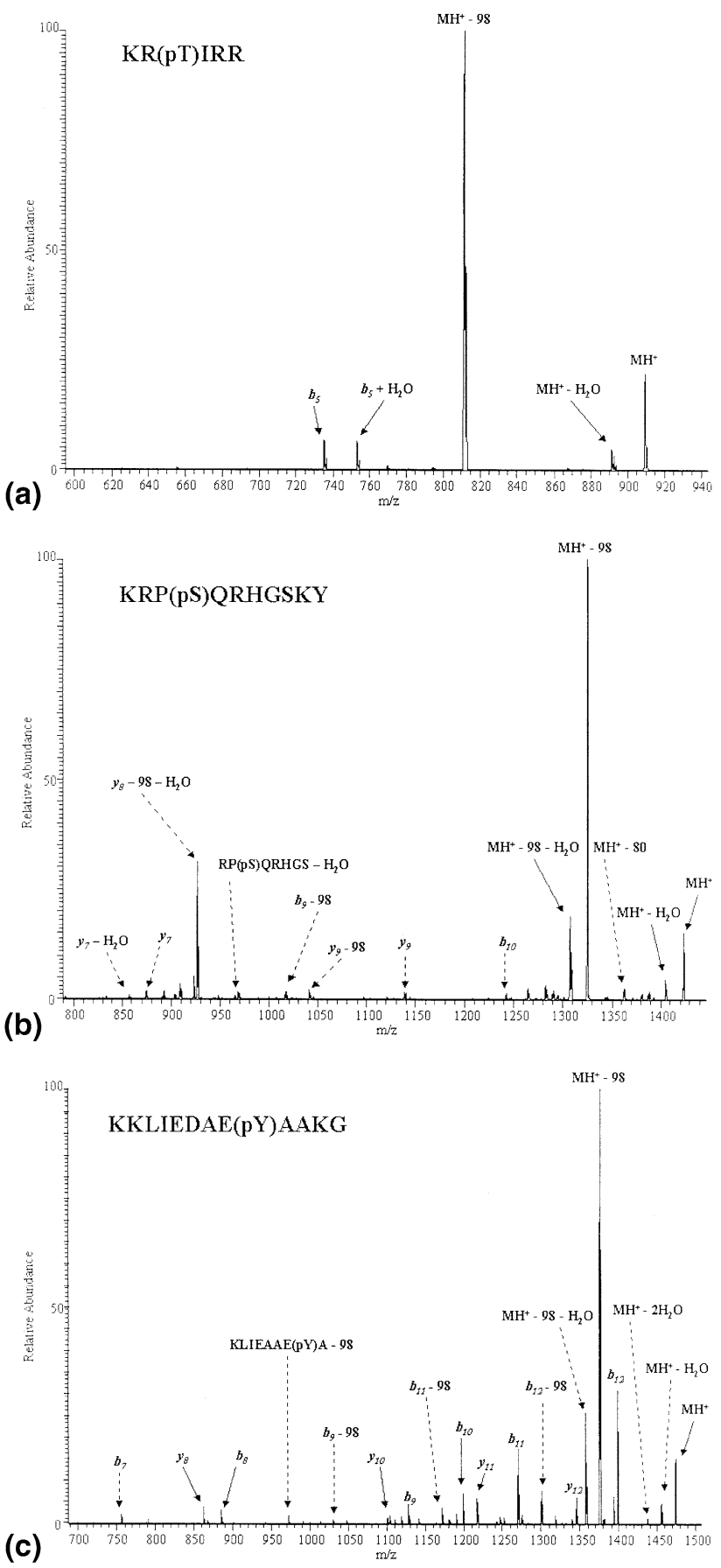

Figure 1. (a) MS/MS of the AP MALDI-genenrated $[\mathrm{M}+\mathrm{H}]^{+}$ ion of $\mathrm{KR}(\mathrm{pT}) \mathrm{IRR}$. Loss of $98 \mathrm{Da}$ from the precursor ion is observed. (b) MS/MS of the AP MALDI-generated $[\mathrm{M}+\mathrm{H}]^{+}$ion of KRP(pS)QRHGSKY. Loss of 98 Da from the precursor ion is observed. (c) MS/MS of the AP MALDI-generated $[\mathrm{M}+\mathrm{H}]^{+}$ion of KKLIEAAE(pY)AAKG. Loss of 98 Da from the precursor ion is observed.

first mechanism involves the transfer of $\mathrm{HPO}_{3}$ to an aspartic acid side chain followed by a cleavage of $\mathrm{H}_{3} \mathrm{PO}_{4}$ and subsequent formation of a succinimide. The second mechanism entails protonation of the phosphate group of phosphotyrosine by an arginine residue followed by the loss of $\mathrm{H}_{3} \mathrm{PO}_{4}$ resulting in a phenyl cation
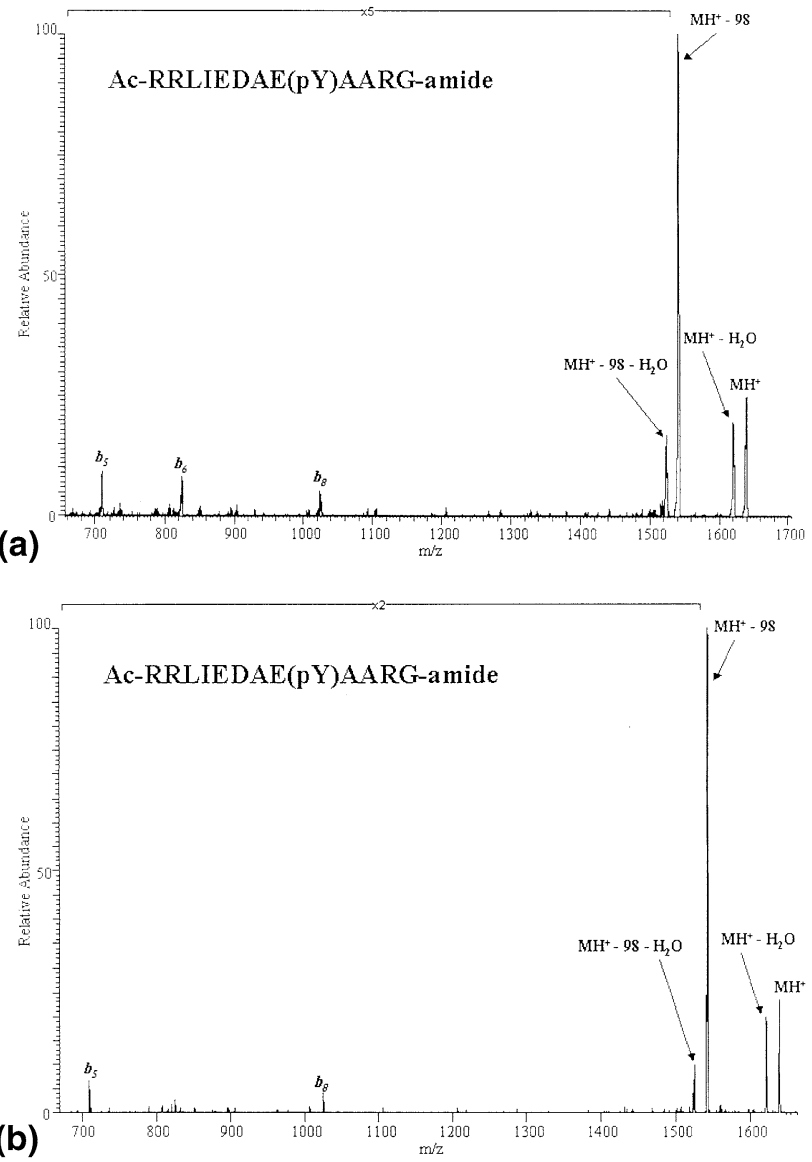

Figure 2. (a) MS/MS of the AP MALDI-generated ion of the phosphotyrosine peptide, RRLIEDAE(pY)AARG. (b) MS/MS of the ESI-generated ion of the phosphotyrosine peptide, RRLIEDA E(pY)AARG.

on the tyrosine residue. The preponderance of various hypotheses indicates that no consensus has yet been reached concerning the processes that govern gas phase dephosphorylation of phosphoserine, phosphothreonine and phosphotyrosine residues.

Members of the c-Src family of protein tyrosine kinases are involved in cell signaling processes and are believed to be integral in cell adhesion and mitosis [23]. The phosphopeptide, RRLIEDAE(pY)AARG, from the pp $60^{\text {src }}$ protein was chosen as the model phosphotyrosine containing peptide for this study. Patients with carcinoma of the colon are found to have elevated levels of specific kinase activity of the proto-oncogene product pp60 $0^{\text {src }}$ [22]. We found this peptide to be relevant to this study because of its important physiological implications and its previous examination by others as a probe of gas phase phosphate loss from tyrosine residues [9, 16].

In the present work, AP MALDI and ESI ITMS are utilized to study phosphate loss from peptides under CID conditions. Primarily, the gas phase processes that occur in phosphotyrosine containing peptides are explored. Using the above peptide as a model, the peptides AAAAADAA(pY)AAAA, RRLIEAAE(pY)AARG, 

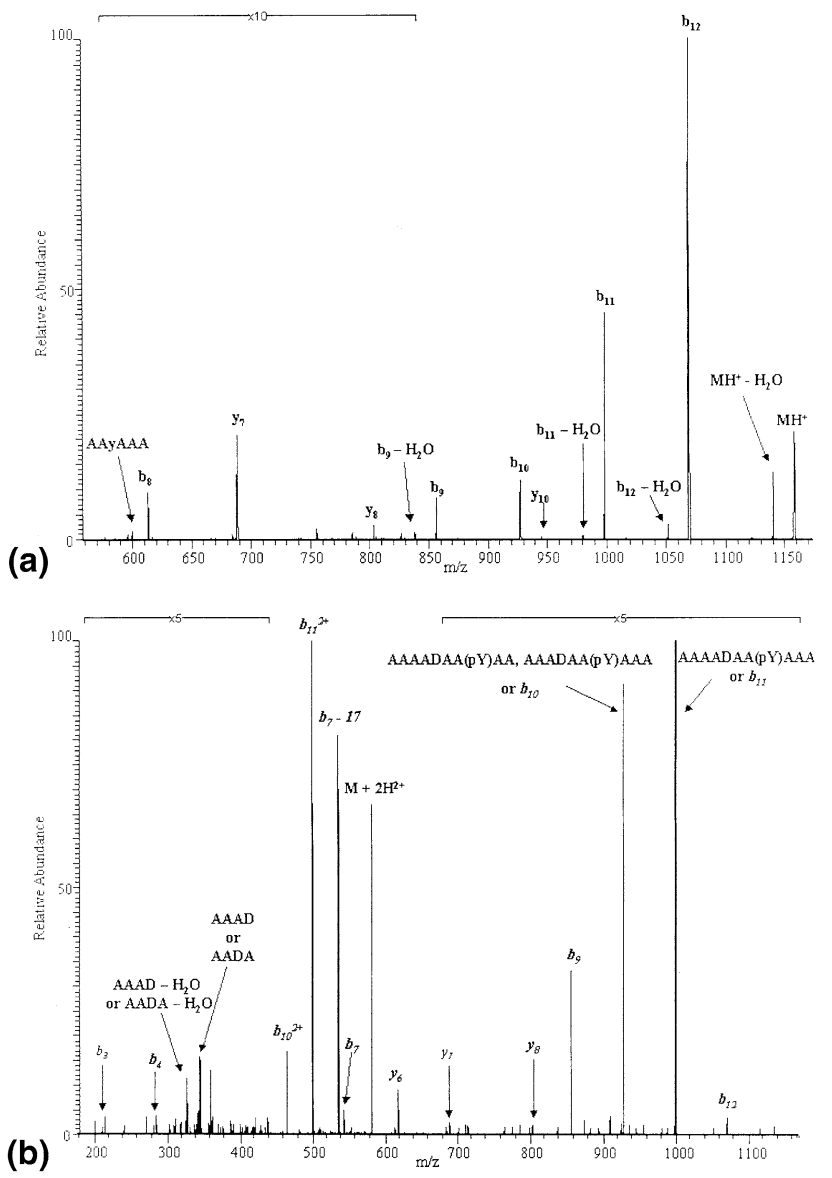

Figure 3. (a) MS/MS of the ESI-generated $[\mathrm{M}+\mathrm{H}]^{+}$ion of AAAAADAA(pY)AAAA. No loss of phosphate from the phosphotyrosine is observed. (b) MS/MS of the ESI-generated [M + $\mathrm{H}]^{2+}$ ion of AAAAADAA(pY)AAAA. No loss of phosphate from the phosphotyrosine is observed, however more backbone fragmentation is derived from the doubly charged species.

KKLIEAAE(pY)AAKG, and AALIEDAE(pY)AAAG were synthesized in order to evaluate the contributions of aspartic acid, arginine, and lysine residues to phosphotyrosine fragmentation in ITMS. In addition, the effects of charge state and structural considerations (i.e., native versus denatured peptides) are examined in this report for their possible roles in phosphate loss from phosphorylated peptides.

\section{Experimental}

\section{Peptides}

Phosphopeptides Ac-RRLIEDAE(pY)AARG-amide and KRP(pS)QRHGSKY were obtained from the University of Michigan Protein and Carbohydrate Facility (Ann Arbor, MI). RRREEE(pS)EEEAA and RRREEE(pT) EEEAA were purchased from AnaSpec (San Jose, CA). All other peptides were synthesized at the Peptide Synthesis Core Facility (Johns Hopkins University School of Medicine, Baltimore, MD). Phosphopeptides analyzed in their native conformations were at a con- centration of $10 \mu \mathrm{M}$ in water and denatured peptides were at a concentration of $10 \mu \mathrm{M}$ in $70 \%$ acetonitrile.

\section{Matrix}

A saturated solution of $\alpha$-cyano-4-hydroxy-cinnamic acid (Sigma, St. Louis, MO) in 50\% ethanol was used for all AP MALDI experiments.

\section{Enzymes}

Sequencing grade trypsin and pronase were acquired from Roche Molecular Biochemicals (Indianapolis, IN). Trypsin was reconstituted in $1 \mathrm{mM} \mathrm{HCl}$ to a concentration of $0.5 \mu \mathrm{g} / \mu \mathrm{L}$ and pronase was reconstituted in water to a concentration of $0.06 \mu \mathrm{g} / \mu \mathrm{L}$.

\section{Enzymatic Digests}

Tryptic digests were carried out by combining $1 \mu \mathrm{L}$ of peptide $(100 \mathrm{pmol} / \mu \mathrm{L}), 2 \mu \mathrm{L}$ of $25 \mathrm{mM}$ ammonium bicarbonate buffer ( $\mathrm{pH} 7.8$ ) and $1 \mu \mathrm{L}$ of trypsin $(0.5$ $\mu \mathrm{g} / \mu \mathrm{L}) .0 .5 \mu \mathrm{L}$ aliquots were applied to the target at 3 , $5,10,20$, and $30 \mathrm{~min}$ intervals and the reaction quenched by the addition of $0.5 \mu \mathrm{L}$ of matrix solution. Pronase digests were performed by combining $2 \mu \mathrm{L}$ of peptide $(100 \mathrm{pmol} / \mu \mathrm{L}), 4 \mu \mathrm{L}$ of $25 \mathrm{mM}$ ammonium bicarbonate buffer $(\mathrm{pH} 7.8)$ and $2 \mu \mathrm{L}$ pronase $(0.06$ $\mu \mathrm{g} / \mu \mathrm{L}$ ). A $0.5 \mu \mathrm{L}$ aliquot of the pronase digest was added to the sample probe and the reaction quenched by the addition of $0.5 \mu \mathrm{L}$ of matrix at $0.5,1$, and $2 \mathrm{~min}$ intervals.

\section{AP MALDI/ITMS}

Mass spectra were obtained on a LCQ quadrupole ion trap mass spectrometer (ThermoFinnigan, San Jose, CA) equipped with an atmospheric pressure matrix-assisted laser desorption/ionization (AP-MALDI) source (Mass Technologies, Burtonsville, MD). A potential of $2.5 \mathrm{kV}$ was applied between the sample target and the inlet capillary. The transfer capillary temperature was set to $200{ }^{\circ} \mathrm{C}$. Samples were prepared by applying $0.5 \mu \mathrm{L}$ of sample solution and $0.5 \mu \mathrm{L}$ of the matrix solution to the target surface and allowing the mixture to dry at room temperature.

\section{ESI/ITMS}

Electrospray ionization/ion trap mass spectrometry (ESI/ITMS) was performed on phosphotyrosine containing peptides. Peptides were analyzed at a concentration of $10 \mu \mathrm{M}$ in $50 \%$ ethanol. The spray voltage was $3.5 \mathrm{kV}$ and the capillary temperature was $200{ }^{\circ} \mathrm{C}$. MS/MS and $\mathrm{MS}^{3}$ spectra were obtained for singly, doubly, and triply charged peptides. 
Table 2. Summary of ESI MS/MS data from singly and multiply charged ions

\begin{tabular}{|c|c|c|c|}
\hline Peptide & $\begin{array}{l}\text { Charge } \\
\text { state }\end{array}$ & $\begin{array}{l}\text { CID backbone } \\
\text { fragmentation }\end{array}$ & $\begin{array}{l}\text { Precursor ion } \\
\text { phosphate loss }\end{array}$ \\
\hline \multirow[t]{2}{*}{ Ac-RRLIEDAE(pY)AARG-amide } & +1 & $\mathrm{~b}$ & $\Delta 98$ \\
\hline & +2 & $b, y$ & $\Delta 98$ \\
\hline \multirow[t]{2}{*}{ AAAAADAA(pY)AAAA } & +1 & $b, y$ and internal & no loss \\
\hline & +2 & $b, y$ and internal & no loss \\
\hline \multirow[t]{3}{*}{ RRLIEAAE(pY)AARG } & +1 & some $b$ and $y$ & $\Delta 98$ \\
\hline & +2 & $b, y$ & $\Delta 98$ \\
\hline & +3 & $\begin{array}{l}a, b, y \text { and internal } \\
\Delta 98: \text { internal }\end{array}$ & $\Delta 98$ \\
\hline \multirow[t]{3}{*}{ KKLIEAAE(pY)AAKG } & +1 & $b, y$ and internal & $\Delta 98$ \\
\hline & +2 & $\begin{array}{l}\text { b, y and internal } \\
\Delta 80: \text { internal } \\
\Delta 98: \text { internal }\end{array}$ & $\Delta 98$ \\
\hline & +3 & $\begin{array}{l}a, b, y \text { and internal } \\
\Delta 80: \text { internal } \\
\Delta 98: \text { internal }\end{array}$ & $\Delta 98$ \\
\hline \multirow[t]{2}{*}{ AALIEDAE(pY)AAAG } & +1 & $b, y$ & no loss \\
\hline & +2 & some $b$ & no loss \\
\hline \multirow[t]{3}{*}{ RRLIEDNEYTARG } & +1 & $b, y$ & $\mathrm{~N} / \mathrm{A}$ \\
\hline & +2 & $\mathrm{~b}, \mathrm{y}$ & $\mathrm{N} / \mathrm{A}$ \\
\hline & +3 & $b, y$ and internal & $\mathrm{N} / \mathrm{A}$ \\
\hline
\end{tabular}

\section{Results and Discussion}

\section{AP MALDI/ITMS}

Full scan and MS/MS spectra of phosphopeptides and non-phosphorylated peptides were obtained. Results for the MS/MS data obtained by AP MALDI/ITMS are summarized in Table 1. Analysis of phosphorylated peptides by AP MALDI/ITMS yielded all singly charged molecular ions. The subsequent MS/MS spectra of these phosphorylated peptides yielded losses of $98 \mathrm{Da}$ from the molecular ion. The results, as seen in Figure 1, are consistent for peptides containing phosphothreonine (Figure 1a), phosphoserine (Figure 1b), and phosphotyrosine (Figure 1c). The loss of $98 \mathrm{Da}$ in the MS/MS spectra of phosphothreonine and phosphoserine was expected, as the bond between the oxygen and alkyl carbon on the threonine and serine side chains is readily broken under CID conditions. However, the 98 Da loss observed in the phosphotyrosine residue was unexpected, because of the inherent resonance stabilization of the phenolic oxygen by the aromatic ring. This stabilization makes cleavage between the phosphorus and the phenolic oxygen more likely, which would result in an $80 \mathrm{Da}$ loss from a phosphotyrosine peptide, instead of the $98 \mathrm{Da}$ loss that is observed.

Previous work by others also noted a 98 Da loss from phosphotyrosine peptides [11, 12, 16], however, the reasons for this $98 \mathrm{Da}$ loss is unclear. In order to explore fragmentation of the phosphate group from tyrosine, we employed the peptide Ac-RRLIEDAE(pY)AARGamide as a model. This peptide had been studied earlier by MALDI PSD, with Annan and Carr reporting a predominant 80 Da loss [9] and Metzger and Hoffmann a major loss of $98 \mathrm{Da}$ and a minor loss of $80 \mathrm{Da}$ [16]. Figure 2a shows the MS/MS spectrum of the AP
MALDI-generated ion of Ac-RRLIEDAE(pY)AARGamide at $\mathrm{m} / \mathrm{z}$ 1640.8. CID of this molecular ion yielded a loss of $98 \mathrm{Da}$, which corresponds to either a direct loss of $\mathrm{H}_{3} \mathrm{PO}_{4}$ from the phosphorylated residue or a sequential loss of $\mathrm{HPO}_{3}$, followed by a loss of $\mathrm{H}_{2} \mathrm{O}$ from another location on the peptide. This loss is evident in the MS/MS spectrum of the peptide by the observation of a peak at $\mathrm{m} / \mathrm{z} 1542.7$, which is $98 \mathrm{Da}$ less than the molecular ion. In contrast to the literature $[9,16]$, no loss of $80 \mathrm{Da}$ is observed from the precursor ion. Figure $2 \mathrm{~b}$ displays the MS/MS spectrum of the singly charged ESI-generated ion of Ac-RRLIEDAE(pY)AARG-amide. These results are in agreement with the AP MALDI data described above.

Using RRLIEDAE(pY)AARG as a model, other peptides were sequenced in order to evaluate the effects of specific residues on phosphate loss from phosphotyrosine peptides. The peptides, AAAAADAA(pY) AAAA and AALIEDAE(pY)AAAG, were constructed in order to study the role of acidic residues, such as aspartic and glutamic acid, in the fragmentation of phosphotyrosine. RRLIEAAE(pY)AARG and KKLIEAAE(pY)AAKG were utilized to study the effects of the basic residues, arginine and lysine, on phosphotyrosine fragmentation.

Phosphotyrosine peptides lacking an arginine or a lysine residue in their sequence did not lose phosphate $\left(\mathrm{H}_{3} \mathrm{PO}_{4}\right)$ under $\mathrm{CID}$ conditions and displayed minimal backbone fragmentation. This is evident in the ESI MS/MS spectra of phosphotyrosine peptide AAAAADAA(pY)AAAA in Figure 3, which does not lose phosphate from either the singly (Figure $3 a$ ) or doubly charged (Figure $3 b$ ) precursor ions. Additionally, no phosphate loss occurs from the peptide AALIE DAE(pY)AAAG (data not shown). These results are 

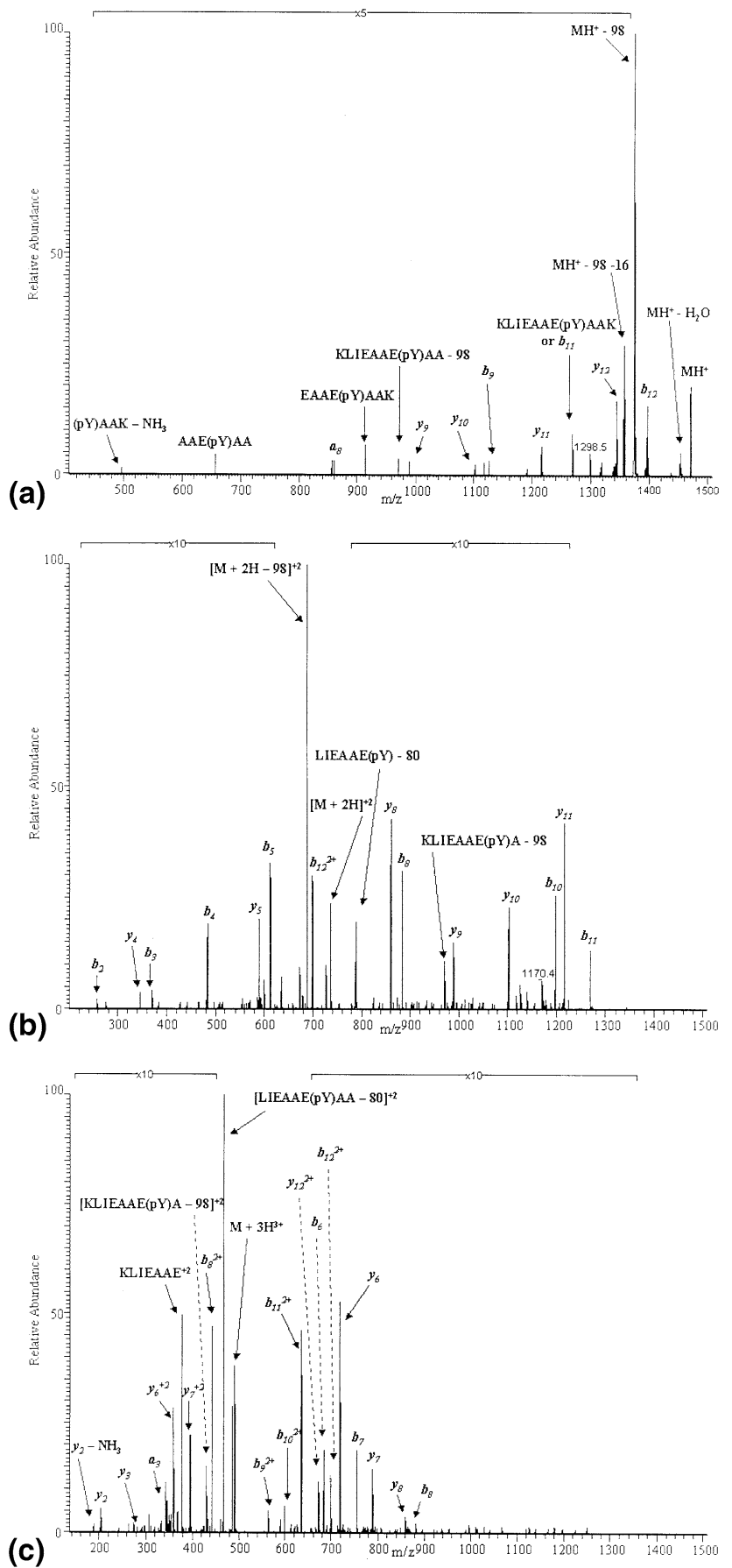

Figure 4. (a) MS/MS of the ESI-generated $[\mathrm{M}+\mathrm{H}]^{+}$ion of KKLIEAAE(pY)AAKG. Phosphate loss is observed as an exclusive loss of $98 \mathrm{Da}$ from the precursor ion. An internal fragment ion containing one lysine displayed a loss of $98 \mathrm{Da}$. (b) MS/MS of the ESI-generated $[\mathrm{M}+\mathrm{H}]^{2+}$ ion of KKLIEAAE(pY)AAKG. Phosphate loss is observed as an exclusive loss of $98 \mathrm{Da}$ from the precursor ion. An internal fragment ion containing one lysine displayed a loss of $98 \mathrm{Da}$. Another internal fragment ion, LIEAAE (pY), showed a loss of $80 \mathrm{Da}$. (c) MS/MS of the ESI-generated [M $+\mathrm{H}]^{3+}$ ion of KKLIEAAE(pY)AAKG. Phosphate loss is observed as an exclusive loss of $98 \mathrm{Da}$ from the precursor ion. A doubly charged internal fragment ion containing one lysine demonstrated a loss corresponding to $98 \mathrm{Da}$. A doubly charged LIEAAE(pY)AA ion lost $80 \mathrm{Da}$. consistent with the AP MALDI data presented in Table 1 and would suggest that the acidic residues in these peptides did not initiate phosphate loss, as previously described in [16].

The phosphotyrosine peptides containing basic residues experienced a 98 Da loss under CID conditions. For example, MS/MS of the AP MALDI-generated ion of RRLIEAAE(pY)AARG (data reported in Table 1) resulted in a precursor ion phosphate loss, corresponding to $98 \mathrm{Da}$. The lysine-containing peptide, KKLIEAA E(pY)AAKG, displayed a similar loss of $98 \mathrm{Da}$ in its MS/MS spectrum (Figure 1c).

Previous work by Metzger and Hoffmann [16] using the peptide RRLIEDAE(pY)AARG as a model suggested that peptide secondary structure might play a role in the phosphate loss from phosphotyrosine. In this particular peptide, the predicted secondary structure would be $\alpha$-helical [16, 24], which would theoretically allow for interactions between the side chains of the aspartic acid residue at position six and the phosphotyrosine residue at position nine and between the side chains of the phosphotyrosine residue and the arginine residue at position twelve. A comparison of the MS/MS spectra of the phosphotyrosine peptides in their native and denatured states was undertaken and the data reported in Table 1. The data shows that the secondary structure of these peptides had no effect on phosphotyrosine's phosphate fragmentation. The results from the denatured peptides are in agreement with native peptides in that the MS/MS spectra of phosphotyrosine peptides containing arginine or lysine residues in their sequence lost phosphate, while those without arginine or lysine residues did not lose phosphate under CID conditions. This is in agreement with the circular dichroism data of Metzger and Hoffmann [16] for the peptide, RRLIEDAE(pY)AARG, which suggests that this peptide does not have sufficient $\alpha$-helical character for the side chain interactions to occur.

\section{ESI/ITMS}

MS/MS of singly and multiply charged phosphopeptide ions generated by ESI were obtained for comparison with the fragmentation patterns of singly charged phosphopeptide ions generated by AP MALDI. The ESI/ITMS results for the phosphopeptides are reported in Table 2.

The precursor ion phosphate losses of singly and multiply charged ions were in agreement with losses associated with singly charged AP MALDI ions; corresponding to a loss of $98 \mathrm{Da}$. For example, MS/MS of the singly charged AP MALDI generated ion of KKLIEAA E(pY)AAKG at $m / z 1472.6$ displayed a 98 Da loss at $m / z$ 1374.6 (Figure 1c). The MS/MS spectrum of the doubly charged ESI generated ion of the same peptide at $\mathrm{m} / \mathrm{z}$ 737.3 (Figure $4 \mathrm{~b}$ ) also showed a loss corresponding to phosphate at the doubly charged fragment peak at $\mathrm{m} / \mathrm{z}$ 687.6. When corrected for charge state, this loss corresponds to a loss of $98 \mathrm{Da}$, which is consistent with the 
Table 3. AP MALDI MS/MS data from enzymatic digests of photophosphorylated peptides

\begin{tabular}{|c|c|c|c|c|}
\hline Peptide & Enzyme & Digest fragment & $\begin{array}{l}\text { CID backbone } \\
\text { fragmentation }\end{array}$ & $\begin{array}{l}\text { Precursor ion } \\
\text { phosphate loss }\end{array}$ \\
\hline \multirow[t]{2}{*}{ Ac-RRLIEDAE(pY)AARG-amide } & Trypsin & RLIEDAE(pY)AAR & $\mathrm{b}, \mathrm{y}$ and internal & $\Delta 98$ \\
\hline & & LIEDAE(pY)AAR & $\begin{array}{l}\mathrm{a}, \mathrm{b}, \mathrm{y} \text { and internal } \\
\Delta 80: \mathrm{a}_{10} \text { and } \mathrm{y}_{7} \\
\Delta 98: \mathrm{b}_{10} \text { and } \mathrm{y}_{6}-\mathrm{y}_{8}\end{array}$ & $\Delta 80, \Delta 98$ \\
\hline \multirow[t]{2}{*}{ RRLIEAAE(pY)AARG } & Trypsin & LIEAAE(pY)AARG & $\begin{array}{l}a, b \text { and } y \\
\Delta 80: a_{10} \text { and } y_{5}\end{array}$ & $\Delta 80, \Delta 98$ \\
\hline & & RLIEAAE(pY)AARG & $\mathrm{b}$ and $\mathrm{y}$ & $\Delta 98$ \\
\hline \multirow[t]{2}{*}{ KKLIEAAE(pY)AAKG } & Trypsin & LIEAAE(pY)AAKG & $\mathrm{b}, \mathrm{y}$ and internal & $\Delta 98$ \\
\hline & & KLIEAAE(pY)AAKG & $a, b, y$ and internal & $\Delta 98$ \\
\hline \multirow[t]{2}{*}{$\mathrm{DRV}(\mathrm{pY})$ IHPF } & Pronase & $\mathrm{DRV}(\mathrm{pY})$ & $b$ and $Y$ & $\Delta 80, \Delta 98$ \\
\hline & Trypsin & $\mathrm{V}(\mathrm{pY}) \mathrm{IHPF}$ & $a, b, y$ and internal & no loss \\
\hline \multirow[t]{2}{*}{ RRREEE(pT)EEEAA } & Trypsin & $\operatorname{REEE}(p T) E E E A A$ & $\begin{array}{l}\mathrm{b} \text { and } \mathrm{y} \\
\Delta 98: \mathrm{b}_{5}-\mathrm{b}_{8}\end{array}$ & $\Delta 98$ \\
\hline & & $\mathrm{EEE}(\mathrm{pY}) \mathrm{EEEAA}$ & $\begin{array}{l}\mathrm{b} \\
\Delta 98: \mathrm{b}_{4}-\mathrm{b}_{8}\end{array}$ & $\Delta 98$ \\
\hline \multirow[t]{2}{*}{ RRREEE(pS)EEEAA } & Trypsin & REEE(pS)EEEAA & $\Delta 98: b_{5}-b_{8}$ & $\Delta 98$ \\
\hline & & $\mathrm{EEE}(\mathrm{pS}) \mathrm{EEEAA}$ & $\begin{array}{l}\mathrm{b} \text { and } \mathrm{y} \\
\Delta 98: \mathrm{b}_{4}-\mathrm{b}_{8}\end{array}$ & $\Delta 98$ \\
\hline RRA(pS)PVA & Trypsin & $\mathbf{R A}(p S) P V A$ & $\begin{array}{l}\mathrm{b} \\
\Delta 98: \mathrm{b}_{3}\end{array}$ & $\Delta 98$ \\
\hline
\end{tabular}

data for the singly charged AP MALDI generated ions. The data for the MS/MS of the triply charged ESI generated ion of this peptide (Figure 4c) shows a similar result. In addition, the MS/MS spectra of both the singly charged AP MALDI and doubly charged ESI generated ions of AAAAADAA(pY)AAAA (Table 1 and Figure $3 b$, respectively) do not undergo the loss of phosphate. CID of doubly and triply charged phosphopeptide ions suggest that multiple charges have no effect on the loss of phosphate from the precursor ion, with major fragmentation corresponding to a 98 Da loss when corrected for charge state. Rather, the increase in charge affects only the degree of backbone fragmentation obtained by CID, with higher levels of backbone fragmentation with increasing charge state. In addition, $\mathrm{MS}^{3}$ experiments were performed on phosphotyrosine peptides that do not have arginine or lysine residues in their sequences (data not shown). Even after performing $\mathrm{MS}^{3}$ experiments, these peptides did not lose phosphate from the phosphotyrosine residue.

\section{The Role of Arginine and Lysine Residues in Phosphate Loss}

Phosphotyrosine. In this work, it was observed that only those phosphotyrosine peptides containing arginine or lysine residues lost phosphate under CID conditions in ITMS. This observation was consistent for both AP MALDI and ESI generated ions (Tables 1 and 2). Enzymatic digests of phosphopeptides were performed in order to evaluate the effects of arginine and lysine residues on phosphate loss. The results of these experiments are compiled in Table 3.

Phosphopeptides were digested with trypsin in order to obtain phosphorylated fragments with a varying number of arginine or lysine residues, ranging from zero to two arginines and/or lysines per fragment. MS/MS of the enzymatic fragments suggests that the presence of arginines and/or lysines in the phosphotyrosine peptide influences the fragmentation of $\mathrm{H}_{3} \mathrm{PO}_{4}$ $(\Delta 98), \mathrm{HPO}_{3}(\Delta 80)$, or $\mathrm{HPO}_{3}$ and $\mathrm{H}_{2} \mathrm{O}(\Delta 98)$ from the peptide. As illustrated in Figure 5, a tryptic fragment of the phosphotyrosine peptide, RRLIEAAE(pY)AARG, containing one arginine residue (Figure 5a) displayed losses of both 80 and $98 \mathrm{Da}$ in the MS/MS spectrum, while a tryptic fragment containing two arginine residues (Figure 5b) lost 98 Da in its MS/MS spectrum. As shown in Figure 6, tryptic fragments of the phosphotyrosine peptide, KKLIEAAE(pY)AAKG, containing one (Figure 6a) or two (Figure 6b) lysine residues exhibited losses of $98 \mathrm{Da}$ in their MS/MS spectra.

In digests of phosphotyrosine peptides, an enzymatic fragment ion with one or more lysine residues or two or more arginine residues always displayed a loss of $98 \mathrm{Da}$ in the MS/MS spectrum. A phosphotyrosine containing peptide fragment with one arginine residue showed precursor ion losses of both $80 \mathrm{Da}$ and $98 \mathrm{Da}$ in its MS/MS spectrum and phosphotyrosine peptides containing zero arginines or lysines did not lose phosphate under CID conditions.

Trypsin and pronase digestions of the peptide DRV(pY)IHPF were carried out in order to determine if other basic residues, such as histidine $\left(\mathrm{pK}_{\mathrm{a}} 6.0\right)$, influenced gas phase phosphate loss. These results are reported in Table 3. MS/MS of the pronase fragment $\mathrm{DRV}(\mathrm{pY})$ yielded losses of $80 \mathrm{Da}$ and $98 \mathrm{Da}$, which is consistent with the MS/MS data of other phosphotyrosine peptides containing one arginine. The MS/MS of the tryptic fragment $\mathrm{V}(\mathrm{pY}) \mathrm{IHPF}$ showed no loss of 
(a)

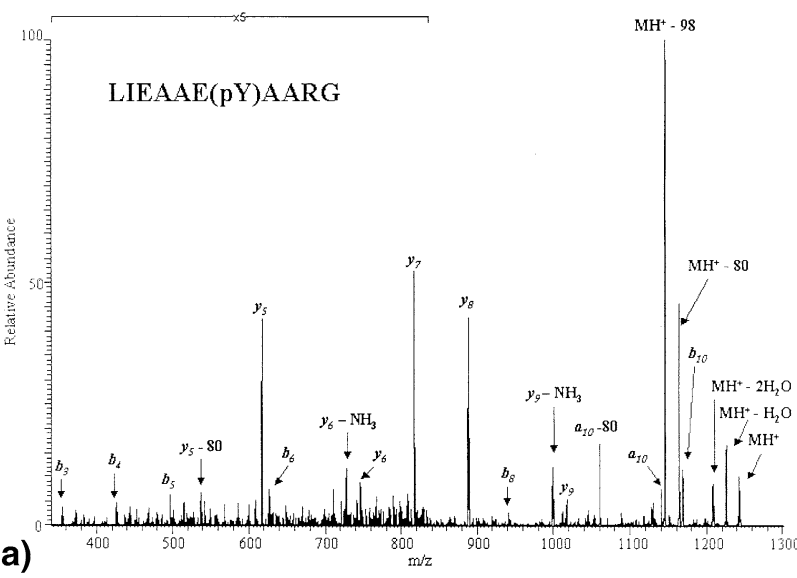

(b)

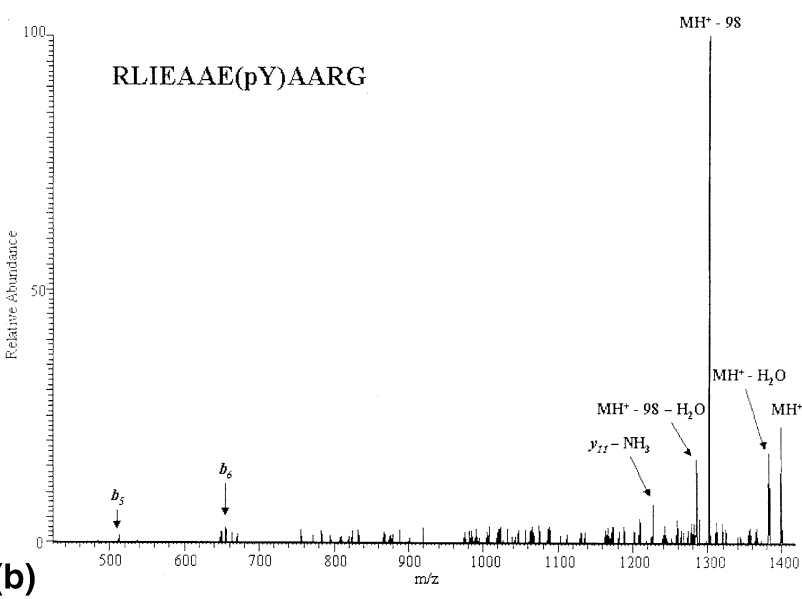

Figure 5. (a) MS/MS of tryptic fragment LIEAAE(pY)AARG. (b) MS/MS of tryptic fragment RLIEAAE(pY)AARG.

phosphate, which would suggest that histidine has no effect on phosphate loss from phosphotyrosine.

The $\delta$-guanido group on the arginine or the amine on lysine may play a role in the reaction that results in dephosphorylation of phosphotyrosine in the gas phase, while the tertiary amine in the imidazole ring of histidine may be unavailable to participate in the dephosphorylation of tyrosine. The phosphotyrosine phosphorous, which is partially positively charged due to the strong electron withdrawing nature of the phenyl ring, may undergo a nucleophilic attack. This could result in cleavage between the phosphorous and the phenolic oxygen, accounting for the loss of $80 \mathrm{Da}$ from the phosphotyrosine residue. The remaining loss of 18 Da needed to explain the observed $98 \mathrm{Da}$ total loss from phosphotyrosine peptides could be in the form of $\mathrm{H}_{2} \mathrm{O}$ loss from elsewhere in the peptide.

The relatively long time scale (milliseconds) employed in the ion trap mass spectrometer may account for the observation of $98 \mathrm{Da}$ losses in phosphotyrosine peptides. The MS/MS spectra resulting from ITMS may be representative of the completed phosphotyrosine peptide fragmentation. This could account for the results in previous reports $[9,16]$ utilizing MALDI PSD, which operates on a much shorter time scale (microsec- onds). These results, showing losses of exclusively 80 $\mathrm{Da}$ [10] or both 80 and $98 \mathrm{Da}$ [17] in the PSD spectra of RRLIEDAE(pY)AARG, may be snapshots of incomplete fragmentation of this peptide.

Alternatively, it may be that the arginine and lysine side chains are interacting directly with the $\pi$-cloud of the phosphotyrosine phenyl ring in a cation- $\pi$ interaction, thus facilitating gas phase phosphate fragmentation [25-27]. Crystal structures of various $\mathrm{SH} 2$ domain phosphotyrosine-peptide complexes depict interactions between the aromatic ring of phosphotyrosine and positively charged residues [26]. Moreover, arginine and lysine residues have been shown to interact directly with the phenyl ring of phosphotyrosine while forming hydrogen bonds with phosphate oxygens. In addition, NMR studies of the active site arginine in the SH2 domain demonstrated interaction between the guanidinium group and the phosphotyrosine ring [28, 29]. This close interaction between basic amino acid side chains and the phosphotyrosine residue may be responsible for the gas phase phosphate loss observed in phosphotyrosine peptides containing arginines or lysines.

Phosphoserine and Phosphothreonine. All phosphoserine and phosphothreonine containing peptides utilized in
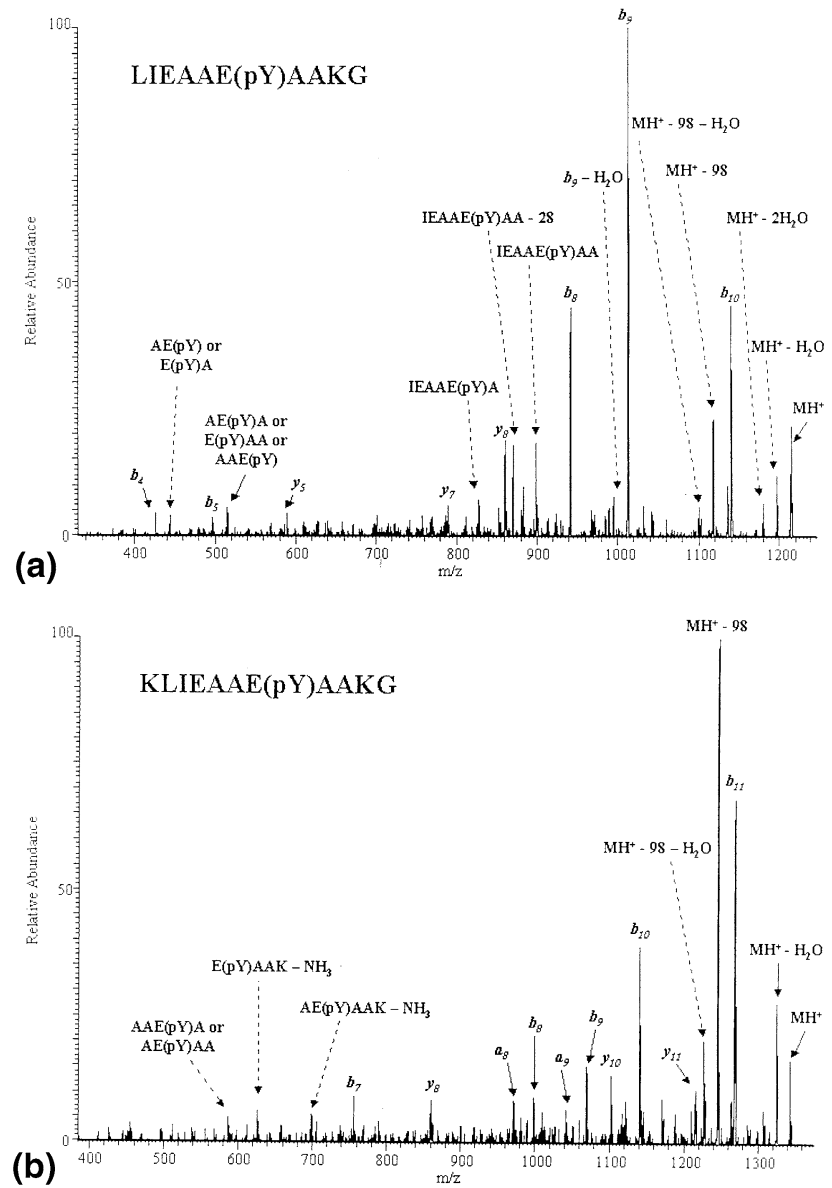

Figure 6. (a) MS/MS of tryptic fragment LIEAAE(pY)AAKG. (b) MS/MS of tryptic fragment KLIEAAE(pY)AAKG. 
this study underwent a loss of $98 \mathrm{Da}$ in their MS/MS spectrum (Table 1). Figures $1 \mathrm{a}$ and $\mathrm{b}$ show the AP MALDI MS/MS spectra of KR(pT)IRR and KRP(pS)QRHGSKY, respectively. Both peptides demonstrate exclusive losses of $98 \mathrm{Da}$, corresponding to $\mathrm{H}_{3} \mathrm{PO}_{4}$, in their MS/MS spectra.

Phosphopeptides RRREEE(pS)EEEAA and RRREEE(pT)EEEAA were digested with trypsin in order to determine whether or not arginine residues influenced phosphate loss from phosphoserine and phosphothreonine residues (Table 3). The tryptic fragments, RREEE(pT)EEEAA, REEE(pT)EEEAA, and EEE(pT)EEEAA of the phosphothreonine peptide, RRREEE(pT)EEEAA were analyzed in order to determine whether basic residues had any influence on phosphate fragmentation from phosphothreonine. Similar studies were carried out on peptides containing phosphoserine residues (Table 3). The MS/MS spectra of enzymatic digestion products containing either zero, one, or two arginine residues were obtained by AP MALDI/ITMS. Regardless of arginine content in the peptide, these phosphoserine and phosphothreonine peptides underwent a phosphate loss, corresponding to $98 \mathrm{Da}$ in their MS/MS spectra. The data suggests that arginine has no influence on the gas phase loss of phosphate from either phosphoserine or phosphothreonine residues.

\section{Conclusion}

AP MALDI and ESI ITMS experiments were carried out on a number of phosphorylated peptides in order to observe gas phase dephosphorylation patterns associated with phosphoserine, phosphothreonine, and phosphotyrosine residues. While phosphoserine and phosphothreonine residues undergo a loss of 98 Da under CID conditions regardless of the peptide amino acid residue content, phosphate loss from phosphotyrosine residues seems to be dependent on the presence of arginine or lysine residues in the peptide sequence.

The data supports two possible routes for the gas phase dephosphoryation of phosphotyrosine. The strong electron withdrawing nature of the phosphotyrosine phenyl ring may cause a partially positively charged phosphate that can be attacked by a nucleophile. An alternative pathway for phosphate loss would involve a cation- $\pi$ interaction between the phenyl group of phosphotyrosine and an arginine or lysine residue. The interaction of these two amino acid side chains may facilitate gas phase phosphate loss from phosphotyrosine.

\section{Acknowledgments}

Funding for this work was provided by a contract (DABT63-99-10006) to RJC from the Defense Advanced Research Project Agency (DARPA) and from NIDA Intramural Research Program, NIDA, NIH. Support for SCM was provided by a NSF-GOALI grant (CHE 9634238). The authors wish to thank Andrew E. Taggi
(Department of Chemistry, Johns Hopkins University) and Professor Douglas P. Ridge (Department of Chemistry and Biochemistry, University of Delaware) for their helpful discussions regarding this manuscript.

\section{References}

1. Laiko, V. V.; Baldwin, M. A.; Burlingame, A. L. Atmospheric Pressure Matrix-Assisted Laser Desorption/Ionization Mass Spectrometry. Anal. Chem. 2000, 72, 652-657.

2. Laiko, V. V.; Moyer, S. C.; Cotter, R. J. Atmospheric Pressure MALDI/Ion Trap Mass Spectrometry. Anal. Chem. 2000, 72, 5239-5243.

3. Moyer, S. C.; Laiko, V. V.; Cotter, R. J. Atmospheric Pressure MALDI/Ion Trap Mass Spectrometry. Proceedings of the 48th ASMS Conference on Mass Spectrometry and Allied Topics; Long Beach, CA, June 2000.

4. Danell, R. M.; Glish, G. L. An Atmospheric Pressure MALDI Probe for Use with ESI Source Interfaces. Proceedings of the 48th ASMS Conference on Mass Spectrometry and Allied Topics; Long Beach, CA, June 2000.

5. Callahan, J. H.; Galicia, M.; Vertes, A. Atmospheric Pressure Matrix-Assisted Laser Desorption Ionization with a Quadrupole Ion Trap. Proceedings of the 48th ASMS Conference on Mass Spectrometry and Allied Topics; Long Beach, CA, June 2000.

6. Moyer, S. C.; Cotter, R. J.; Woods, A. S. Atmospheric Pressure MALDI/Ion Trap Mass Spectrometry of Peptide-Peptide Interactions. Proceedings of the 49th ASMS Conference on Mass Spectrometry and Allied Topics; Chicago, IL, May 2001.

7. Marzilli, L. M.; Moyer, S. C.; Cotter, R. J. Analysis of Posttranslational Modifications by Atmospheric Pressure MALDI/Ion Trap Mass Spectrometry. Proceedings of the 49th ASMS Conference on Mass Spectrometry and Allied Topics; Chicago, IL, May 2001.

8. Reid, G. E.; Simpson, R. J.; O'Hair, R. A. J. Leaving Group and Gas Phase Neighboring Group Effects in the Side Chain Losses from Protonated Serine and its Derivatives. J. Am. Soc. Mass Spectrom. 2000, 11, 1047-1060.

9. Annan, R. S.; Carr, S. A. Phosphopeptide Analysis by MatrixAssisted Laser Desorption Time-of-Flight Mass Spectrometry. Anal. Chem. 1996, 68, 3413-3421.

10. Busman, M.; Schey, K. L.; Oatis, J. E.; Knapp, D. R. Identification of Phosphorylation Sites in Phosphopeptides by Positive and Negative Mode Electrospray Ionization-Tandem Mass Spectrometry. J. Am. Soc. Mass Spectrom. 1996, 7, 243-249.

11. Qin, J.; Chait, B. T. Identification and Characterization of Posttranslational Modifications of Proteins by MALDI Ion Trap Mass Spectrometry. Anal. Chem. 1997, 69, 4002-4009.

12. DeGnore, J. P.; Qin, J. Fragmentation of Phosphopeptides in an Ion Trap Mass Spectrometer. J. Am. Soc. Mass Spectrom. 1998, 9, $1175-1188$.

13. Zhang, X.; Herring, C. J.; Romano, P. R.; Szczepanowska, J.; Brzeska, H.; Hinnebusch, A. G.; Qin, J. Identification of Phosphorylation Sites in Proteins Separated by Polyacrylamide Gel Electrophoresis. Anal. Chem. 1998, 70, 2050-2059.

14. Tholey, A.; Reed, J.; Lehmann, W. D. Electrospray Tandem Mass Spectrometric Studies of Phosphopeptides and Phosphopeptide Analogues. J. Mass Spectrom. 1999, 34, 117-123.

15. Hoffmann, R.; Metzger, S.; Spengler, B.; Otvos, L. Sequencing of Peptides Phosphorylated on Serines and Threonines by Post-Source Decay in Matrix-Assisted Laser Desorption/Ionization Time-of-flight Mass Spectrometry. J. Mass Spectrom. 1999, 34, 1195-1204.

16. Metzger, S.; Hoffmann, R. Studies on the Dephosphorylaiton of Phosphotyrosine-Containing Peptides During Post-Source Decay in Matrix-Assisted Laser Desorption/Ionization. J. Mass Spectrom. 2000, 35, 1165-1177. 
17. Huddleston, M. J.; Annan, R. S.; Bean, M. F.; Carr, S. A. Selective Detection of Phosphopeptides in Complex Mixtures by Electrospray Liquid Chromatography/Mass Spectrometry. J. Am. Soc. Mass Spectrom. 1993, 4, 710-717.

18. Dass, C.; Mahalakshmi, P. Amino Acid Sequence Determination of Phosphoenkephalins Using Liquid Secondary Ionization Mass Spectrometry. Rapid Commun. Mass Spectrom. 1995, 9, 1148-1154.

19. Gibson, B. W.; Cohen, P. Liquid Secondary Ion Mass Spectrometry of Phosphorylated and Sulfated Peptides and Proteins. Methods Enzymol. 1990, 193, 480-501.

20. Cohen, P.; Gibson, B. W.; Holmes, C. F. Analysis of the in vivo Phosphorylation States of Proteins by Fast Atom Bombardment Mass Spectrometry and Other Techniques. Methods Enzymol. 1991, 201, 153-168.

21. Carr, S. A.; Huddleston, M. J.; Annan, R. S. Selective Detection and Sequencing of Phosphopeptides at the Femtomole Level by Mass Spectrometry. Anal. Biochem. 1996, 239, 180-192.

22. Cam, W. R.; Masaki, T.; Shiratori, Y.; Kato, N.; Ikenoue, T.; Okamoto, M.; Igarashi, K.; Sano, T.; Omata, M. Reduced C-Terminal Src Kinase Activity is Correlated Inversely with pp60 $60^{\text {c-src }}$ Activity in Colorectal Carcinoma. Cancer 2001, 92, $61-70$.
23. Brickell, P. M. Receptor and Non-Receptor Protein-Tyrosine Kinases. In Protein Phosphorylation in Cell Growth Regulation; Clemens, N. J., Ed.; Harwood Academic Publishers, GmbH: Amsterdam, 1996; 19-58.

24. nnPredict, University of California at San Fransisco, www. cmpharm.ucsf.edu.

25. Gallivan, J. P.; Dougherty, D. A. Cation- $\pi$ Interactions in Structural Biology. Proc. Natl. Acad. Sci. U.S.A. 1999, 96, 9459-9464.

26. Ma, J. C.; Dougherty, D. A. The Cation- $\pi$ Interaction. Chem. Rev. 1997, 97, 1303-1324.

27. Mecozzi, S.; West, A. P.; Dougherty, D. A. Cation- $\pi$ Interactions in Aromatics of Biological and Medicinal Interest: Electrostatic Potential Surfaces as a Useful Qualitative Guide. Proc. Natl. Acad. Sci. U.S.A. 1996, 93, 10566-10571.

28. Pascal, S. M.; Yamazaki, T.; Singer, A. U.; Kay, L. E.; FormanKay, J. D. Structural and Dynamic Characterization of the Phosphotyrosine Binding Region of Src Homology 2 Domain-Phosphopeptide Complex by NMR Relaxation, Proton Exchange, and Chemical Shift Approaches. Biochemistry 1995, 36, 11353-11362.

29. Pascal, S. M.; Singer, A. U.; Yamazaki, T.; Kay, L. E.; FormanKay, J. D. Structural and Dynamic Characterization of an SH2 Domain-Phosphopeptide Complex by NMR Approaches. Biochem. Soc. Trans. 1995, 4, 729-733. 